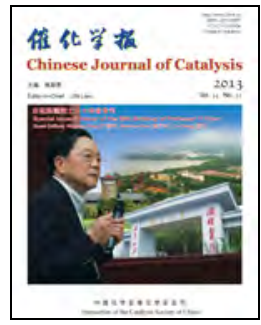

Article (Dedicated to Professor Yi Chen on the occasion of his 80th birthday)

\title{
Synthesis of in-situ surfactant-free Pd nanoparticle catalysts for the synthesis of aromatic azo compounds and for unsaturated bond hydrogenation by hydrogen transfer
}

\author{
Xin Wang †, Jiaqing Wang †, Fenqiang Qi, Lei Hu, Xinming Li, Xueqin Cao, Hongwei Gu* \\ Key Laboratory of Organic Synthesis of Jiangsu Province, College of Chemistry, Chemical Engineering and Materials Science, Soochow University, \\ Suzhou 215123, Jiangsu, China
}

\section{A R T I C L E I N F O}

Article history:

Received 19 June 2013

Accepted 22 July 2013

Published 20 November 2013

Keywords:

Nanocatalyst

Palladium

Transfer hydrogenation

In-situ synthesis

Azo

\begin{abstract}
A B S T R A C T
We developed a simple and efficient method to synthesize aromatic azos by hydrogen transfer using palladium(II) acetylacetonate as a catalyst and isopropyl alcohol as a hydrogen source. Furthermore, this system also showed catalytic potential for the hydrogenation of carbonyl groups or $\mathrm{C}=\mathrm{C}$ bonds with yields up to $\sim 97 \%$.
\end{abstract}

(C) 2013, Dalian Institute of Chemical Physics, Chinese Academy of Sciences. Published by Elsevier B.V. All rights reserved.

\section{Introduction}

Hydrogen transfer catalyzed by heterogeneous transition metal complexes has found widespread use in the reduction of organic compounds recently [1-11], and this competes with hydrogenation using molecular hydrogen. The success of this technique is due to its operational simplicity, high selectivity [12-15], and the reduced risks associated with the application of inflammable hydrogen gas. Despite notable achievements over the last few decades, the search for a facile, cost-effective, and environmentally benign procedure that avoids the use of expensive and hazardous transition metals, hazardous complexes or toxic chemicals is of continuing interest to synthetic chemists for different catalytic reductions [9, 11, 16-18].

Aromatic azo compounds, as important industrial products and analytical reagents, have been widely applied in various fields such as drugs, organic dyes, food additives, and materials exhibiting photochemical properties [19-23]. Therefore, the preparation of aromatic azo compounds by an environmentally benign and an industrially applicable process attracts attention [24-27]. The synthesis of azo compounds is often carried out by the reduction of nitroaromatics with lead metal or by the oxidation of anilines from lead tetraacetate [28-30], which involves the frequent use of toxic transition metals. Alternatively, Grirrane et al. [31] introduced a novel method to prepare aromatic azo compounds from aromatic anilines in the presence of Au-based catalysts under 5 atm of oxygen pressure. Moreover, they also demonstrated that the azo compound can be obtained from the corresponding nitroaromatics through a two-step, one-pot reaction by combining the reduction of the

\footnotetext{
*Corresponding author. Tel: +86-512-65880905; Fax: +86-512-65882030; E-mail: hongwei@suda.edu.cn

†Xin Wang and Jiaqing Wang contributed equally.

This work was supported by the National Natural Science Foundation of China (21003092) and the Key Project of Chinese Ministry of Education (211064).
} 
nitroaromatic and the oxidation of the aniline under $9 \mathrm{~atm}$ of hydrogen and $5 \mathrm{~atm}$ of oxygen [32]. It is worth mentioning that molecular hydrogen was used as a reducing agent, but it ignites easily and presents considerable hazards, particularly on large scale. Herein, we report aromatic azo formation by a transfer reduction process using hydrogen donors. This process has real and potential advantages such as the absence of gas containment and pressure vessels, and simple solution agitation.

Pd catalysts play an important role in hydrogenation and coupling reactions in organic synthesis. Novel catalysts such as Pd-based nanomaterials [26, 33-37] or surfactant-free systems with higher catalytic activity have emerged recently. For example, surfactant-free $\mathrm{PdCl}_{2}$ catalyzes the Suzuki coupling reaction in water [38], palladium(II) acetate $\left(\mathrm{Pd}(\mathrm{OAc})_{2}\right)$ works as a highly active catalyst for the Heck reactions of aryl chlorides in the absence of an organic ligand [39], and surfactant-free $\mathrm{Pd}(\mathrm{OAc})_{2}$ promotes the direct arylation of furans in high yield [40]. Inspired by these studies, we used a surfactant-free Pd catalyst to synthesize both symmetric and asymmetric azo compounds from a wide range of substituted nitroaromatics and through a one-step reductive reaction. We obtained the target azo compounds in good to excellent yields. In addition, our system is also highly efficient for the catalytic hydrogenation of different unsaturated bonds in the presence of a $\mathrm{C}=0$ and $\mathrm{C}=\mathrm{C}$ bonds under the same mild conditions. We expect that the surfactant-free Pd-catalyzed transfer hydrogenation system can be widely used to synthesize valuable azo compounds, alcohols, and saturated compounds.

\section{Experimental}

\subsection{General}

The aromatic nitro compounds were purchased from Sinopharm Chemical Reagent Co. Ltd. Palladium(II) acetylacetonate $\left(\mathrm{Pd}(\mathrm{acac})_{2}\right)$ was purchased from Sino-platinum Metal Co. Ltd. All materials were used without further purification. Transmission electron microscopy (TEM) measurements were conducted using a JEOL JEM-200CX instrument at an accelerating voltage of $200 \mathrm{kV}$. The product mixtures were analyzed by GC (VARIAN CP-3800 GC, HP-5 capillary column, FID detector) and GC-MS (VARIAN 450-GC \& VARIAN 240-GC) equipped with a CP8944 capillary column $(30 \mathrm{~m} \times 0.25 \mathrm{~mm})$ and an FID detector. The NMR spectra were measured on a spectrometer at $400 \mathrm{MHz}$ for ${ }^{1} \mathrm{H}$ and $100 \mathrm{MHz}$ for ${ }^{13} \mathrm{C}$ in $\mathrm{CDCl}_{3}$ solution.

\subsection{Typical catalytic transfer hydrogenation procedure}

To a reaction tube equipped with a magnetic stirrer an appropriate amount of $\mathrm{Pd}(\mathrm{acac})_{2}(2-3 \mathrm{mg}), \mathrm{KOH}(112 \mathrm{mg}, 2$ mmol), nitrobenzene (102 $\mu \mathrm{L}, 1 \mathrm{mmol})$, isopropyl alcohol (2 $\mathrm{mL})$, and deionized water $(0.25 \mathrm{~mL})$ were added. The air in the tube was then exchanged 3 times with $1 \mathrm{~atm}$ of $\mathrm{N}_{2}$. Finally, the tube was immersed in an oil bath at $100^{\circ} \mathrm{C}$ in a sealed $\mathrm{N}_{2}$ system. After stirring for $24 \mathrm{~h}$ at $100^{\circ} \mathrm{C}$, the mixture was cooled to room temperature. A sample of the mixture was immediately analyzed by GC and GC-MS.

\section{Results and discussion}

To find optimal conditions for the reductive coupling reaction, we used nitrobenzene as the model substrate to test the effect of different bases on the catalytic activity and selectivity of our system. This consists of $1 \mathrm{mmol}$ nitrobenzene, 5-6 mg $\operatorname{Pd}(\mathrm{acac})_{2}$ as catalyst, $2 \mathrm{~mL}$ isopropyl alcohol as a hydrogen donor, and $0.25 \mathrm{~mL}$ deionized water as solvent. As shown in Table 1, aniline was the only product found when using the weak bases $\mathrm{K}_{2} \mathrm{CO}_{3}$ or $\left(\mathrm{C}_{2} \mathrm{H}_{5}\right)_{3} \mathrm{~N}$, and the conversion was less than $5 \%$. $\left(\mathrm{CH}_{3}\right)_{3} \mathrm{COK}$ (Table 1, entry 6 ) gave a high yield for the catalytic conversion at the same base concentration, but it had a relatively low selectivity for the generation of azobenzene compared with $\mathrm{NaOH}$ (Table 1, entry 3) or $\mathrm{KOH}$ (Table 1, entry 5). Considering the relatively higher price and larger molecular weight of $\left(\mathrm{CH}_{3}\right)_{3} \mathrm{COK}, \mathrm{NaOH}$ or $\mathrm{KOH}$ are more suitable for industrial application. We found that an increase in the ratio of $\mathrm{KOH}$ in the mixture increased the conversion and selectivity (Table 2). The yield of azobenzene increased and was $86.7 \%$ when 4 equivalents of $\mathrm{KOH}$ were used (Table 2, entry 4).

A photograph of azobenzene formation is shown in Fig. 1. The clear yellow solution turned dark brown after $18 \mathrm{~h}$ of reac-

\section{Table 1}

Effect of bases on the nitrobenzene coupling reaction.

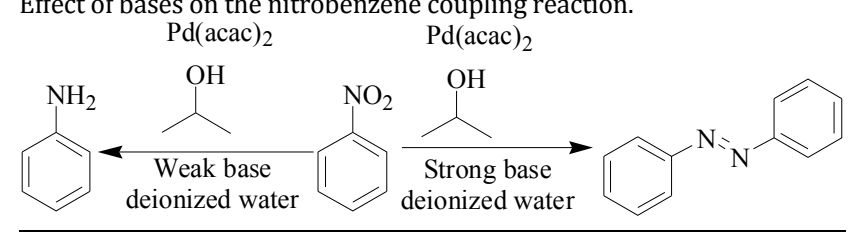

\begin{tabular}{lccccc}
\hline \multirow{2}{*}{ Entry } & \multirow{2}{*}{ Base } & Conversion ${ }^{\mathrm{a}}$ & \multicolumn{3}{c}{ Selectivity a (\%) } \\
\cline { 4 - 6 } & & $(\%)$ & Azo- & Azoxy- & Aniline \\
\hline 1 & $\mathrm{~K}_{2} \mathrm{CO}_{3}$ & 4.9 & - & - & 100 \\
2 & $\left(\mathrm{C}_{2} \mathrm{H}_{5}\right)_{3} \mathrm{~N}$ & 0.8 & - & - & 100 \\
3 & $\mathrm{NaOH}$ & 19.4 & 8.5 & 86.0 & 5.5 \\
4 & $\mathrm{KOH}$ & $>99$ & 86.7 & - & 13.3 \\
5 & $\mathrm{KOH}$ & 57.2 & 14.8 & 75.0 & 10.2 \\
6 & $\left(\mathrm{CH}_{3}\right)_{3} \mathrm{COK}$ & 92.7 & 5.7 & 87.2 & 7.1 \\
\hline
\end{tabular}

Reactions condiction: $\mathrm{Pd}(\mathrm{acac})_{2}$ catalyst 5-6 mg, nitrobenzene $1 \mathrm{mmol}$ base $1 \mathrm{mmol}$, isopropyl alcohol $2 \mathrm{~mL}$, deionized water $0.25 \mathrm{~mL}, 100{ }^{\circ} \mathrm{C}$, $18 \mathrm{~h}$. ${ }^{\mathrm{a}} \mathrm{GC}$ result. $\mathrm{b} 4 \mathrm{mmol}$ base.

\section{Table 2}

Azobenzene formation from nitrobenzene using different amounts of $\mathrm{KOH}$ and $\mathrm{H}_{2} \mathrm{O}$.

\begin{tabular}{|c|c|c|c|c|c|c|c|c|}
\hline \multirow{2}{*}{ Entry } & \multirow{2}{*}{$\begin{array}{c}t \\
\text { (h) }\end{array}$} & \multirow{2}{*}{$\begin{array}{c}i-\mathrm{PrOH} \\
(\mathrm{mL})\end{array}$} & \multirow{2}{*}{$\begin{array}{l}\mathrm{H}_{2} \mathrm{O} \\
(\mathrm{mL})\end{array}$} & \multirow{2}{*}{$\begin{array}{c}\mathrm{KOH} \\
(\mathrm{mmol})\end{array}$} & \multirow{2}{*}{$\begin{array}{c}\text { Conversion a } \\
(\%)\end{array}$} & \multicolumn{3}{|c|}{ Selectivity a (\%) } \\
\hline & & & & & & Azo- & Azoxy- & Aniline \\
\hline 1 & 12 & 2 & 0.25 & 4 & $>99$ & 44.6 & 34.2 & 21.2 \\
\hline 2 & 18 & 2 & 0.10 & 4 & $>99$ & 75.3 & - & 24.7 \\
\hline 3 & 18 & 2 & 0.20 & 4 & 100 & 77.0 & - & 23.0 \\
\hline 4 & 18 & 2 & 0.25 & 4 & $>99$ & 86.7 & - & 13.3 \\
\hline 5 & 18 & 2 & 0.50 & 4 & $>99$ & 84.6 & - & 15.4 \\
\hline 6 & 18 & 2 & 0.75 & 4 & $>99$ & 51.0 & 34.8 & 14.2 \\
\hline 7 & 18 & 2 & 1.00 & 4 & $>99$ & 26.6 & 51.2 & 22.2 \\
\hline 8 & 24 & 2 & 0.25 & 4 & 100 & 84.4 & - & 15.6 \\
\hline 9 & 18 & 2 & - & 4 & 100 & 48.4 & - & 51.6 \\
\hline 10 & 18 & 2 & 0.25 & 1 & 57.2 & 14.8 & 75.0 & 10.2 \\
\hline 11 & 18 & 2 & 0.25 & 2 & $>99$ & 12.4 & 81.1 & 6.5 \\
\hline 12 & 18 & 2 & 0.25 & 3 & $>99$ & 50.4 & 39.3 & 10.3 \\
\hline 13 & 18 & 2 & 0.25 & 5 & 100 & 38.5 & 52.1 & 9.4 \\
\hline
\end{tabular}

Reaction conditions: Pd(acac) $)_{2}$ catalyst $5-6 \mathrm{mg}$, nitrobenzene $1 \mathrm{mmol}$, isopropyl alcohol $2 \mathrm{~mL}$, deionized water little, $100^{\circ} \mathrm{C}$. a $\mathrm{GC}$ result. 


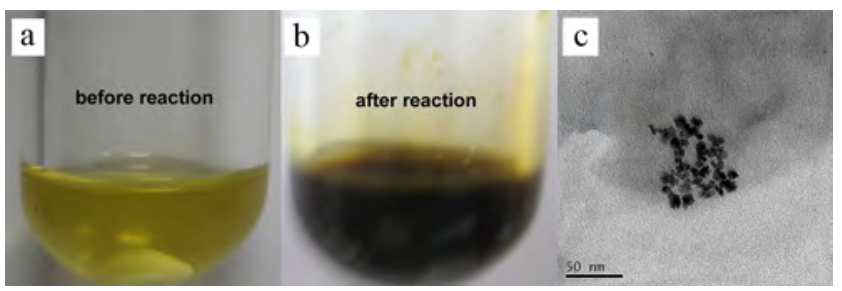

Fig. 1. Photographs of the reactant before (a) and after (b) reaction, and TEM image of the in-situ synthesized Pd nanoparticles (c).

tion. Pd nanoparticles with an average diameter of $5 \mathrm{~nm}$ were separated from the reactant by high-speed centrifugation and this is shown in Fig. 1(c). The pre-prepared Pd nanoparticles had low catalytic activities ( $20 \%$ conversion over $25 \mathrm{~h})$ compared with the in-situ formed Pd nanoparticles in the Pd(acac)2 catalytic system. Time dependent analysis revealed that azobenzene was converted by the reduction of azoxybenzene. The yields of azobenzene and azoxybenzene were $44.6 \%$ and $34.2 \%$, respectively, over $12 \mathrm{~h}$. The highest yield was achieved after $18 \mathrm{~h}$, and no obvious increase in yield was observed after $24 \mathrm{~h}$. We also found that the amount of water present in the reaction also played an important role in the reaction and af-

Table 3

Pd-catalyzed transfer hydrogenation for aromatic azo compound formation from different corresponding nitroaromatic compounds.

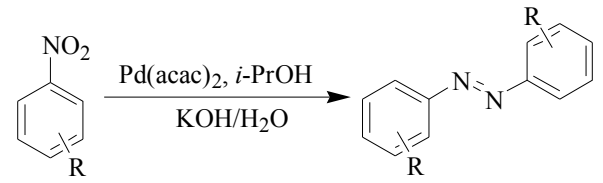

\begin{tabular}{|c|c|c|c|c|}
\hline Entry & Nitro- & Azo & \multicolumn{2}{|c|}{$t(\mathrm{~h})$ Yield a $(\%)$} \\
\hline $1 \mathrm{~b}$ & & & 18 & 86.7 \\
\hline 2 & & & 24 & 69.0 \\
\hline 3 & & & 24 & 85.9 \\
\hline 4 & & & 30 & 19.4 \\
\hline 5 & & & 24 & 57.8 \\
\hline 6 & & & 24 & 40.6 \\
\hline 7 & & & 24 & 60.7 \\
\hline 8 & & & 18 & 36.8 \\
\hline 9 & & & 10 & 11.7 \\
\hline 10 & & & 24 & 16.6 \\
\hline 11 & & & 10 & 13.0 \\
\hline
\end{tabular}

Reaction conditions: $\mathrm{Pd}(\mathrm{acac})_{2}$ catalyst 5-6 mg, nitroaromatic compound $1 \mathrm{mmol}$, KOH $4 \mathrm{mmol}$, isopropyl alcohol $2 \mathrm{~mL}$, deionized water $0.25 \mathrm{~mL}, 120^{\circ} \mathrm{C}$. ${ }^{\mathrm{a}}$ Isolated yield. ${ }^{\mathrm{b}} 100^{\circ} \mathrm{C}$.
Table 4

Transfer hydrogenation synthesis of asymmetric azobenzenes from an equimolar mixture of nitroaromatics.

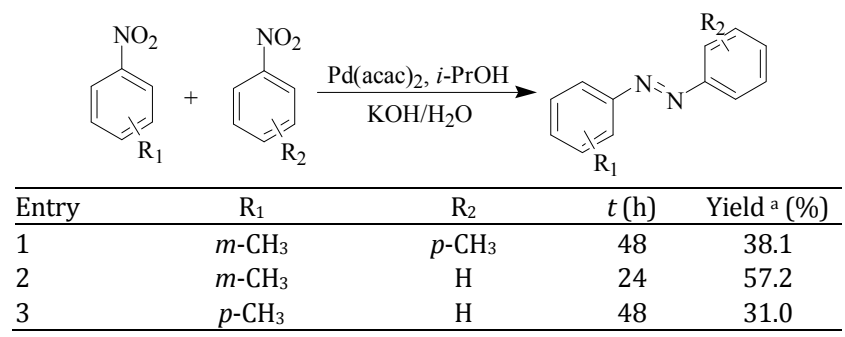

Reaction conditions: $\mathrm{Pd}(\mathrm{acac})_{2}$ catalyst 5-6 mg, nitroaromatic compound $0.5 \mathrm{mmol}, \mathrm{KOH} 4 \mathrm{mmol}$, isopropyl alcohol $2 \mathrm{~mL}$, deionized water $0.25 \mathrm{~mL}, 120^{\circ} \mathrm{C} .{ }^{\mathrm{G}} \mathrm{GC}$ result.

fected the catalytic conversion to azobenzene (Table 2). Trace amounts of water can promote transfer hydrogenation and increase the yield of azobenzene greatly. However, when excessive water is present, a significant decrease in the yield of the target product results. The optimal amount of water for efficient azobenzene conversion was found to be $0.25 \mathrm{~mL}$, resulting in a final yield of $86.7 \%$.

Under optimized conditions for the formation of azobenzene from nitrobenzene, other symmetrical substituted azobenzenes were also obtained from their corresponding nitrobenzenes. As shown in Table 3, we obtained aromatic azos from $p$ - and $m$-nitrotoluene (Table 3, entries 2 and 3) in $69.0 \%$ and $85.9 \%$ total yields, respectively. Because of steric hindrance from the methyl group, the conversion of $o$-nitrotulene was only $19.4 \%$ (Table 3 , entry 4 ). The other electron-rich nitroaromatic compounds that contain methoxy and $\mathrm{N}, \mathrm{N}$-dimethyl groups also gave the corresponding aromatic azo compounds in good to excellent yields (36.8\%-60.7\%) under these conditions (Table 3, entries 5-8). On the other hand, the electron-poor nirtoaromatic compounds transformed to their corresponding aromatic azo compounds in relatively low yields (Table 3, entries 8-11). Furthermore, asymmertrical aromatic azo compounds were successfully synthesized in good yields of $38.1 \%, 57.2 \%$, and $31.0 \%$ using two different substituted nitrobenzenes as reactants (Table 4, entries 1-3).

A proposed mechanism for azobenzene formation from nitrobenzene is shown in Scheme 1. Pd(acac)2 is reduced by isopropyl alcohol to form Pd clusters under strong base conditions. Further reduction to form Pd-H then occurs [2]. Nitrobenzene is reduced by $\mathrm{Pd}-\mathrm{H}$ to nitrosobenzene, which is quickly

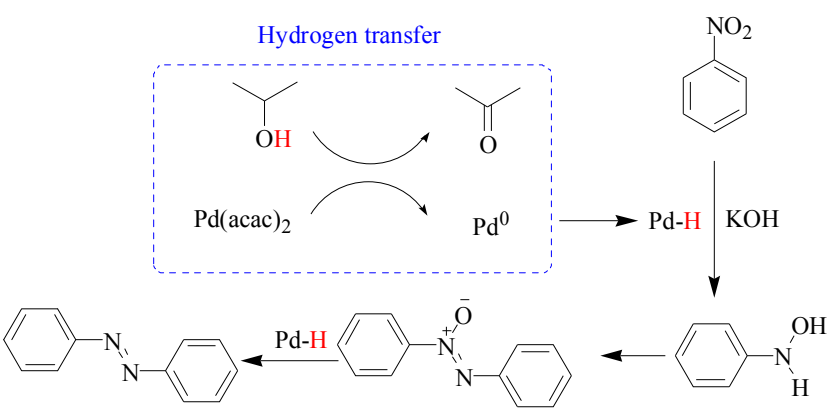

Scheme 1. Proposed mechanism for azobenzene formation by hydrogen transfer. 
Table 5

Pd-catalyzed transfer hydrogenation of unsaturated bonds.

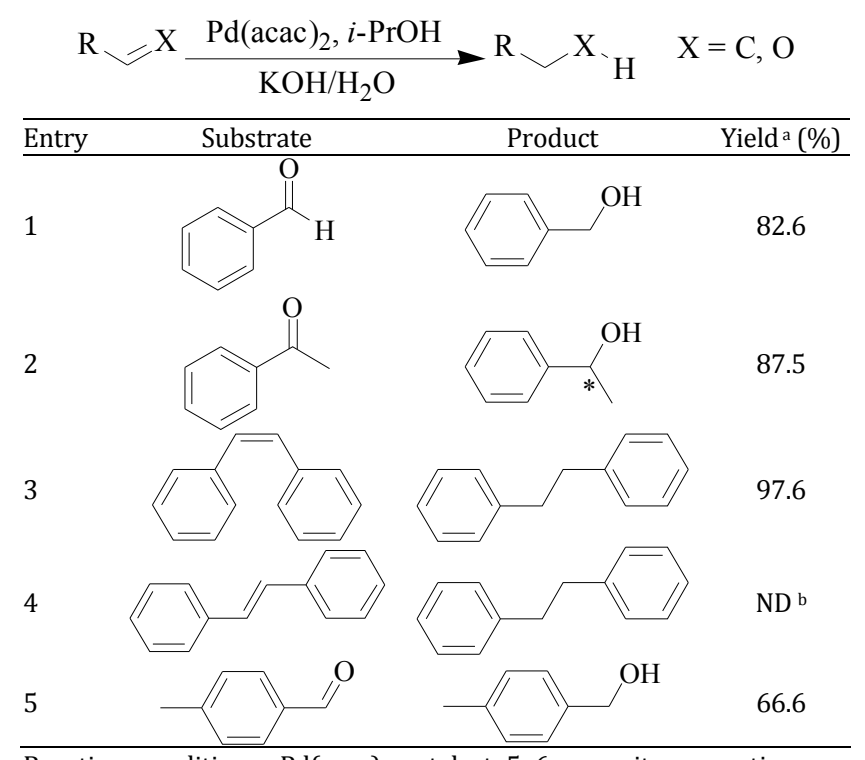

Reaction conditions: $\mathrm{Pd}(\mathrm{acac})_{2}$ catalyst 5-6 mg, nitroaromatic compound $0.5 \mathrm{mmol}$, KOH $4 \mathrm{mmol}$, isopropyl alcohol $2 \mathrm{~mL}$, deionized water $0.25 \mathrm{~mL}, 120^{\circ} \mathrm{C} .{ }^{\mathrm{a}} \mathrm{GC}$ result. ${ }^{\mathrm{b}}$ Not detected.

converted to $\mathrm{N}$-hydroxybenzenamine. Under strong base conditions (such as for $\mathrm{KOH}$ ), the $N$-hydroxybenzenamine couples to nitrosobenzene and dehydrates to give azoxybenzene, which can be further reduced by $\mathrm{Pd}-\mathrm{H}$ to form azobenzene.

To extend the applications of our catalytic system we performed more challenging chemoselective transfer hydrogenation of unsaturated bonds in the presence of $\mathrm{C}=\mathrm{O}$ and $\mathrm{C}=\mathrm{C}$ bonds. Under the optimized conditions shown in Table 5, our surfactant-free Pd catalyst also worked well for the selective hydrogenation of unsaturated bonds through transfer hydrogenation. The yield of optically active alpha-methylbenzyl alcohol from acetophenone was $87.5 \%$ (Table 5, entry 2). In addition, a higher reaction activity toward the transfer hydro- genation of $\mathrm{C}=\mathrm{C}$ bonds on cis-stilbene resulted, and the yield of 1,2-diphenylethane was $97.6 \%$ (Table 5, entry 3). However, the transfer hydrogenation process does not take place on trans-stilbene (Table 5, entry 4), and the yields determined for the hydrogenation of benzaldehyde and $p$-methyl substituted benzaldehyde are $82.6 \%$ and $66.6 \%$, respectively (Table 5, entries 1 and 5).

\section{Conclusions}

We developed a convenient surfactant-free catalyst system based on $\mathrm{Pd}(\mathrm{acac})_{2}$ for the transfer hydrogenation of nitroaromatic compounds to give symmetrical and asymmetrical aromatic azo compounds and also for the transfer hydrogenation of unsaturated bonds. Furthermore, the in-situ formed surfactant-free nanocatalyst shows higher activity compared with a pre-prepared nanocatalyst. Our catalytic system makes use of isopropyl alcohol as a hydrogen donor. This has many merits such as environmental friendliness and ease of handling. Further studies into this surfactant-free catalytic system are being carried out in our lab to expand its applications.

\section{References}

[1] Brieger G, Nestrick T J. Chem Rev, 1974, 74: 567

[2] Johnstone R A W, Wilby A H, Entwistle I D. Chem Rev, 1985, 85: 129

[3] Zassinovich G, Mestroni G, Gladiali S. Chem Rev, 1992, 92: 1051

[4] Fujii A, Hashiguchi S, Uematsu N, Ikariya T, Noyori R. J Am Chem Soc, 1996, 118: 2521

[5] Noyori R, Hashiguchi S. Acc Chem Res, 1997, 30: 97

[6] Palmer M J, Wills M. Tetrahedron Asymmetry, 1999, 10: 2045

[7] Blaser H U, Malan C, Pugin B, Spindler F, Steiner H, Studer M. Adv Synth Catal, 2003, 345: 103

[8] Clapham S E, Hadzovic A, Morris R H. Coord Chem Rev, 2004, 248: 2201

[9] Gladiali S, Alberico E. Chem Soc Rev, 2006, 35: 226

[10] Samec J S M, Backvall J E, Andersson P G, Brandt P. Chem Soc Rev, 2006, 35: 237

\section{Graphical Abstract}

Chin. J. Catal., 2013, 34: 2084-2088 doi: 10.1016/S1872-2067(12)60665-2

\section{Synthesis of in-situ surfactant-free Pd nanoparticle catalysts for the synthesis of aromatic azo compounds and for unsaturated bond hydrogenation by hydrogen transfer}

Xin Wang, Jiaqing Wang, Fenqiang Qi, Lei Hu, Xinming Li, Xueqin Cao, Hongwei Gu*

Soochow University

A simple and efficient method to synthesize aromatic azos by hydrogen transfer has been developed. $\mathrm{Pd}(\mathrm{acac})_{2}$ was selected as a catalyst and isopropyl alcohol was selected as the hydrogen source. This system also works well for the hydrogenation of unsaturated compounds containing a carbonyl group or $\mathrm{C}=\mathrm{C}$ bond with yields up to $\sim 97 \%$.

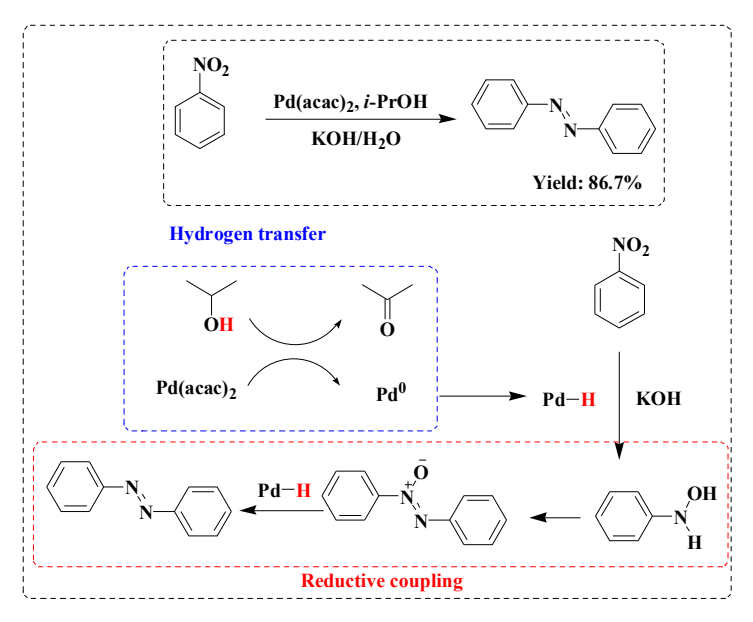


[11] Ikariya T, Blacker A J. Acc Chem Res, 2007, 40: 1300

[12] Rhyoo H Y, Park H J, Suh W H, Chung Y K. Tetrahedron Lett, 2002, 43: 269

[13] Saluzzo C, Lemaire M. Adv Synth Catal, 2002, 344: 915

[14] Miecznikowski J R, Crabtree R H. Organometallics, 2004, 23: 629

[15] Baratta W, Chelucci G, Gladiali S, Siega K, Toniutti M, Zanette M, Zangrando E, Rigo P. Angew Chem Int Ed, 2005, 44: 6214

[16] Koike T, Ikariya T. Adv Synth Catal, 2004, 346: 37

[17] Rueping M, Sugiono E, Azap C. Theissmann T, Bolte M. Org Lett, 2005, 7: 3781

[18] Jagadeesh R V, Wienhoefer G, Westerhaus F A, Surkus A E, Junge H, Junge K, Beller M. Chem Eur J, 2011, 17: 14375

[19] Hoult J R S. Drugs, 1986, 32(Suppl 1): 18

[20] Stick R V, Mocerino M, Franz D A. J Chem Edu, 1996, 73: 540

[21] Orban M, Kurin-Csorgei K, Zhabotinsky A M, Epstein I R. J Am Chem Soc, 1998, 120: 1146

[22] Kuwabara T, Nakajima H, Nanasawa M, Ueno A. Anal Chem, 1999, 71: 2844

[23] Hunger K. Industrial Dyes: Chemistry, Properties, Applications. Weinheim: Wiley-VCH, 2003

[24] Srinivasa G R, Abiraj K, Gowda D C. Tetrahedron Lett, 2003, 44: 5835
[25] Moglie Y, Vitale C, Radivoy G. Tetrahedron Lett, 2008, 49: 1828

[26] Hu L, Cao X Q, Shi L Y, Qi F Q, Guo Z Q, Lu J M, Gu H W. Org Lett, 2011, 13: 5640

[27] Zhao R, Tan C Y, Xie Y H, Gao C M, Liu H X, Jiang Y Y. Tetrahedron Lett, 2011, 52: 3805

[28] Wenkert E, Wickberg B. J Am Chem Soc, 1962, 84: 4914

[29] Baumgarten H E, Staklis A, Miller E M. J Org Chem, 1965, 30: 1203

[30] Wenkert E, Angell E C. Synth Commun, 1988, 18: 1331

[31] Grirrane A, Corma A, Garcia H. Science, 2008, 322: 1661

[32] Grirrane A, Corma A, Garcia H. Nat Protoc, 2010, 5: 429

[33] Teng X W, Han W Q, Ku W, Huecker M. Angew Chem Int Ed, 2008, 47: 2055

[34] Huang X Q, Zheng N F. J Am Chem Soc, 2009, 131: 4602

[35] Yuan Q Zhuang J, Wang X. Chem Commun, 2009: 6613

[36] Liang H W, Liu S, Gong J Y, Wang S B, Wang L, Yu S H. Adv Mater, 2009, 21: 1850

[37] Wang J J, Chen Y G, Liu H, Li R Y, Sun X L. Electrochem Commun, 2010, 12: 219

[38] Mondal M, Bora U. Green Chem, 2012, 14: 1873

[39] Kleist W, Proeckl S S, Koehler K. Catal Lett, 2008, 125: 197

[40] Dong J J, Roger J, Pozgan F, Doucet H. Green Chem, 2009, 11: 1832

\title{
原位合成无表面活性剂纳米钯用于催化氢转移反应合成偶氮类化合物及 对不饱和双键的还原
}

\author{
汪欣, 王佳庆, 戚芬强, 胡 磊, 李新明, 曹雪琴, 顾宏伟 ${ }^{*}$ \\ 苏州大学材料与化学化工学部, 江苏省有机化学省重点实验室, 江苏苏州 215123
}

摘要: 以乙酰丙酮钯作为催化剂前体, 异丙醇作为氢源, 在碱性的反应过程中原位得到纳米尺度的钯纳米颗粒, 并进一步得到钯氢活性结构, 实现硝基的还原及氮氮键的偶联. 该催化体系还可以实现 $\mathrm{C}=\mathrm{C}$ 和 $\mathrm{C}=\mathrm{O}$ 键的有效还原. 这类原位得到的钯纳米催化材 料表面裸露, 因而具有更高的催化活性.

关键词: 纳米催化剂; 钯; 转移氢化; 原位合成; 偶氮

收稿日期: 2013-06-19. 接受日期: 2013-07-22. 出版日期: 2013-11-20.

*通讯联系人. 电话: (0512)65880905; 传真: (0512)65882030; 电子信箱: hongwei@suda.edu.cn

基金来源：国家自然科学基金(21003092); 教育部重点项目(211064).

本文的英文电子版由Elsevier出版社在ScienceDirect上出版(http://www.sciencedirect.com/science/journal/18722067). 